\title{
Plastic litter in the sea
}

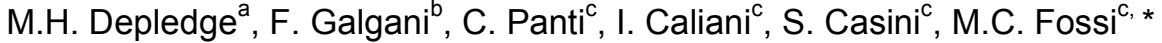

\author{
${ }^{a}$ European Centre for Environment and Human Health, University of Exeter Medical School, Heavitree Road, \\ Exeter EX1 2LU, United Kingdom \\ ${ }^{\mathrm{b}}$ Ifremer, Immeuble Agostini, ZI Furiani, 20600 Bastia, Corsica, France \\ ${ }^{\mathrm{c}}$ Dipartimento di Scienze Fisiche, della Terra e dell'Ambiente, Università di Siena, Via P.A. Mattioli 4, 53100 \\ Siena, Italy \\ *: Corresponding author : M.C. Fossi, tel.: +390577 232913 ; fax: +39 0577232930 ; \\ email address : fossi@unisi.it
}

\begin{abstract}
:
On June 2013 a workshop at the University of Siena (Italy) was organized to review current knowledge and to clarify what is known, and what remains to be investigated, concerning plastic litter in the sea. The content of the workshop was designed to contribute further to the European Marine Strategy Framework Directive (MSFD) following an inaugural workshop in 2012. Here we report a number of statements relevant to policymakers and scientists that was overwhelming agreement from the participants. Many might view this as already providing sufficient grounds for policy action. At the very least, this early warning of the problems that lie ahead should be taken seriously, and serve as a stimulus for further research.
\end{abstract}

\section{Highlights}

Plastic litter is ubiquitous in the oceans, from the coast far out to sea, and onto the sea floor. Micro-debris are considered as one of the main global emerging environmental threats. The EU Marine Strategy Framework Directive includes marine litter monitoring (descriptor 10). The present workshop was designed to contribute further to the EU MSFD implementation.

Keywords : European MSFD ; Marine litter ; Microplastics

\section{Introduction}

Plastic litter is now almost ubiquitous in the World's oceans, extending from the coast far out to sea, and down onto the sea floor. Macroscopic plastic (bottles, plastic bags, old toys, etc.) is in evidence on most tourist beaches, in harbours and marinas, and can be readily spotted from the decks of ferryboats, cruise ships and leisure craft. One of the main causes of this global problem is increasing plastic production. The annual production has increased dramatically from 1.5 million tonnes in the 1950s to approximately 280 million tonnes in 2011. Microplastic fragments (smaller than $5 \mathrm{~mm}$ ) potentially less obvious nanoscale plastic, is readily detectable in sand, sediment and even in marine biota. The latter may originate directly in the micro or nano forms, or result from the breakdown or abrasion of larger pieces of plastic. Microplastics have been accumulating in oceans globally over at least the last four 
decades and have invaded even the most remote marine environments. Knowledge about the effects of this micro-debris is limited, but nonetheless, a horizon scan of global conservation issues recently identified microplastics as one of the main global emerging environmental threats.

Numerous non-governmental organisations, wildlife charities and environmental agencies have drawn attention to the plastic litter issue, yet the scale of the problem is not widely appreciated by the public or politicians. Few, if any, practical measures have been put in place to manage the situation. Concerns extend from the unsightliness of macroplastics affecting coastal tourism, to various effects on ecosystem structure and functions, through adverse impacts on particular species and even the death of individuals (Browne et al. 2011).

Recently, a significant positive relationship between microplastics abundance and human population-density was demonstrated. Since the human population continues to increase, the prevalence of microplastics will also probably increase (Rochman et al. 2013).

Academics and other researchers have now published several authoritative reports on the effects of plastic litter on marine birds, turtles, marine mammals and other marine vertebrates and invertebrates (Wright et al. 2013). Their studies have identified plastic fragments in the water column, in sandy and muddy sediment and in the guts, respiratory structures and tissues of marine species.

On the $5^{\text {th }}$ and $6^{\text {th }}$ June, 2013 , ca. 100 scientists from 6 countries met for a workshop at the University of Siena, Italy, to review current knowledge and to clarify what is known, and what remains to be investigated, concerning plastic litter in the sea. The content of the workshop was designed to contribute further to the European Marine Strategy Framework Directive (MSFD) following an inaugural workshop in 2012 (see Fossi et al 2012). In addition, a number of statements relevant to policymakers were prepared by the organisers at the end of the meeting which are presented here, and which had the overwhelming support of the workshop participants.

\section{What we know concerning plastic litter in the sea}

Several key facts were highlighted at the workshop:

1) Plastic litter is diverse and now very widely distributed in the marine environment.

2) Many kinds of plastic litter are extremely persistent, often for several decades. 
3) Some kinds of marine organisms are particularly vulnerable to plastic litter, including turtles, marine mammals, suspension feeders and deposit feeders.

4) Some plastics components and their constituent chemicals can be transferred through marine food webs (eg. phthalates).

5) Plastic litter can play a role in facilitating the introduction of invasive species into new localities, thereby influencing both biodiversity and ecosystem structure and functions in some areas.

6) The use of plastics is continuing unabated and will increase in the future.

7) Hydrodynamics and degradability determine the fate of litter at sea.

8) Policymakers, politicians and the public remain largely unaware of the extent of the problem and the magnitude of the threat to marine ecosystems.

\section{Emerging questions}

Following the presentation of research papers at the workshop and in subsequent discussions of each session, a number of questions were identified where further research is required to provide answers. They included the following:

1) How much plastic is getting into the marine environment each year?

2) What are the key sources?

3) What are geographic distributions of plastic litter of different sizes?

4) What are the relative proportions of macro, micro and nanoplastic entering the marine environment and which pose the greatest threat?

5) Where do the different types of plastic litter accumulate?

6) How long does each type persist?

7) Is plastic taken up by marine organisms?

8) Is it damaging to them? Is harm well understood?

9) Which kinds of marine organisms most impacted by macro and micro plastics?

10) What are the mechanisms by which damage occurs? 
11) How does plastic interact with other environmental pollutants and influence their toxicity?

12) What is the extent of economic, environmental and human health costs resulting from the presence of plastic litter in the marine environment?

\section{What can be done?}

During the course of the workshop, various needs and measures were discussed that might form the basis for beginning to address threats posed by plastic litter. They included:

1) the need to increase awareness of the scale and severity of the issue through public education programmes,

2) clear identification of who is responsible for managing plastic production and levels of release into the environment,

3) provision of guidelines on the safe disposal of plastics,

4) development of regulations to ensure the safe disposal of plastic - and their enforcement,

5) reduction of the use of plastics worldwide through international agreements,

6) finding environmentally friendly alternative to plastics,

7) development and implementation of programmes for the collection and proper disposal of plastics (for example, beach clean ups, collection for recycling and reuse, etc.),

8) monitoring trends and effects of marine litter at sea,

9) evaluation of the presence and effects of marine debris (particularly microplastic) in marine environment using marine organisms as sentinel species and applying new integrated monitoring tools.

\section{Summary and Conclusions}

There is clearly much to be done to bring the issue of plastic litter in the seas to the attention of the public, policymakers and politicians. Fortunately, the European Commission and other funding organisations around the World have at 
last begun to support research work in this area (see for example, EU projects such as CLEANSEA, MICRO, PERSEUS, MARELITT, MARLISCO, KIMO, etc.). Nonetheless, positive action to curtail and manage of the use of plastics and their disposal is still urgently needed. In this regard, within the European MSFD a proper descriptor (Descriptor 10) was dedicated to marine litter. Task group 10 defines marine litter as "any persistent, manufactured or processed solid material discarded, disposed of or abandoned in the marine and coastal environment" (Galgani et al. 2010) with a view to using mitigation measures to achieve the Good Environmental Status in European waters by 2020.

A recent initiative (July 2013) was proposed by the University of Siena, under the umbrella of the United Nations Sustainable Development Solutions Network MED Solution (directed by Professor Jeffrey D. Sachs - Earth Institute, Columbia University). The main objective of the Solution Project (PLASTIC-BUSTERS) will be to evaluate the presence and effects of marine debris (particularly microplastics) in the Mediterranean environment using marine organisms as sentinel species and applying a new integrated monitoring tool. The international project will help to reinforce existing Mediterranean international efforts to harmonize monitoring and mitigation activities in the entire basin.

In the final session of the Siena workshop, three statements were presented to the participants:

i) Do you agree that there is robust scientific evidence that individuals of some species of marine organisms have already been adversely affected by plastic litter in the seas?

ii) Do you agree that marine ecosystem services are being adversely affected by plastic litter?

iii) Do you agree that there is robust evidence that plastic litter has, in some cases, damaged human health, wellbeing or prosperity?

There was overwhelming agreement from the participants (and no voices of dissent) as to the veracity of these statements. Many might view this as already providing sufficient grounds for policy action. At the very least, this early warning of the problems that lie ahead should be taken seriously, and as a stimulus for further research.

Further details of research into the impact of plastic litter in the marine environment and particularly the potential use of large marine vertebrates (ranging from large pelagic fish, sea turtles, sea birds and cetaceans) in determining the environmental status of marine ecosystems (descriptors1, 8 and 10 - Directive 2008/56/EC of the European Parliament and of the Council of 17 June 2008) will 
be reported in the proceedings of the 2013 workshop to be published in a special issue of Marine Environmental Research in 2014.

170

\section{Acknowledgement}

The Workshop was sponsored by SIBM (Società Italiana di Biologia Marina) and CNR Oristano and supported by Society of Environmental Toxicology and Chemistry (SETAC - Italian Branch), Tuscany Region and Accademia dei Fisiocritici.

\section{References}

Browne, M.A., Crump, P., Niven, S.J., Teuten, E., Tonkin, A., Galloway, T., Thompson, R., 2011. Accumulation of microplastic on shorelines worldwide: sources and sinks. Environ. Sci. Technol. 45 (21), 9175-9.

Galgani, F., Fleet, D., Van Franeker, J., Katsanevakis, S., Maes, T., Mouat, J., Oosterbaan, L., Poitou, I., Hanke, G., Thompson, R., Amato, E., Birkun, A., Janssen, C., 2010. Marine Strategy Framework Directive-Task Group 10 Report Marine Litter. Scientific and Technical Research Series. Office for Official Publications of the European Communities, 48, Luxembourg.

Fossi, M.C., Casini, S., Caliani, I., Panti, C., Marsili, L., Viarengo, A., Giangreco, R., Notarbartolo di Sciara, G., Serena, F., Ouerghi, A., Depledge, M.H., 2012. The role of large marine vertebrates in the assessment of the quality of pelagic marine ecosystems. Mar. Environ. Res. 77, 156-8.

Rochman, C.M., Browne, M.A., Halpern, B.S., Hentschel, B.T., Hoh, E., Karapanagioti, H.K., Rios-Mendoza, L.M., Takada, H., The, S., Thompson, R.C., 2013. Policy: Classify plastic waste as hazardous. Nature. 494 (7436), 169-71.

Wright, S.L., Thompson, R.C., Galloway, T.S., 2013. The physical impacts of microplastics on marine organisms: a review. Environ. Poll. 178, 483-92. 